\title{
Albumin marks pseudopodia of astrocytoma cells responding to hepatocyte growth factor
}

\section{or serum}

\author{
Marie E Beckner ${ }^{1}$, Zhe Zhang ${ }^{2}$, Naomi R Agostino ${ }^{3}$, Billy W Day ${ }^{2,4}$ and Ian F Pollack ${ }^{3}$ \\ ${ }^{1}$ Department of Pathology, University of Pittsburgh, Pittsburgh, PA, USA; ${ }^{2}$ Department of Pharmaceutical \\ Sciences, University of Pittsburgh, Pittsburgh, PA, USA; ${ }^{3}$ Department of Neurosurgery, University of \\ Pittsburgh, Pittsburgh, PA, USA and ${ }^{4}$ Department of Chemistry, University of Pittsburgh, Pittsburgh, PA, USA
}

\begin{abstract}
It is well accepted that dysfunction in the blood brain barrier (BBB) allows permeation of albumin from the bloodstream into astrocytic brain tumors, especially glioblastomas, the most aggressive astrocytomas. In vitro, bovine serum albumin (BSA) aids functional cell assays by maintaining cytokines and growth factors in solution and delivering its cargo of fatty acids. Earlier, we showed that BSA was prominent in lysates prepared from pseudopodia formed by $\mathrm{U} 87$ astrocytoma cells. The present studies investigated the association of albumin with pseudopodia formed by U87 and LN229 astrocytoma cells. With hepatocyte growth factor (HGF) stimulation, cell migration was enhanced and BSA, especially its dimerized form, was prominent in pseudopodia compared to unmigrated cells on one-dimensional gels and immunoblots. When lysates were equalized for levels of glyceraldehyde-3-phosphate dehydrogenase, the rise for BSA levels in pseudopodia vs migrated cells was comparable or greater than levels noted for established pseudopodial proteins, $\beta$-actin and ezrin. The increase for dimerized BSA in pseudopodia compared to unmigrated cells was greater than the rise in levels of $\beta$-actin, ezrin, HGF, and phosphorylated Met when pseudopodia were harvested from filters with $1 \mu \mathrm{m}$ pores using either cell line. Fluorescein (F)-labeled BSA co-localized with HGF on actin-rich cellular protrusions and with CM-Dil labeled pseudopodial plasma membranes. The F-BSA highlighted small, individual pseudopodial profiles more so than complex pseudopodial networks (reticulopodia) or unmigrated cells. Labeled human serum albumin also decorated pseudopodia preferentially. Albumin's association with pseudopodia may help to explain its selective accumulation in astrocytomas in vivo. The leaky BBB permits serum albumin to enter the microenvironment of astrocytomas thus allowing their invasive cells contact with serum albumin as a source of fatty acids that would be useful for remodeling cell membranes in pseudopodia. Thus, albumin potentially aids and marks invasion as it accumulates in these tumors.
\end{abstract}

Laboratory Investigation (2006) 86, 1103-1114. doi:10.1038/labinvest.3700470; published online 11 September 2006

Keywords: pseudopodia; albumin; hepatocyte growth factor; cell migration; astrocytoma

Malignant astrocytomas are lethal, invasive brain tumors that resist all known treatments, primarily because of their infiltrative growth. Breakdown of the blood brain barrier (BBB), a characteristic feature of astrocytomas, allows permeation of human serum albumin (HSA) into the tumors. Albumin in the interstitial fluid of the brain flows along the common routes of tumor invasion through white matter tracts. ${ }^{1}$ Investigating the localization of blood components, such as serum albumin, to migrating

Correspondence: Dr ME Beckner, MD, Department of Pathology, University of Pittsburgh Medical Center, 200 Lothrop Street, PUH, Room A-515, Pittsburgh, PA 15213, USA.

E-mail: becknerme@upmc.edu

Received 21 April 2006; revised 20 July 2006; accepted 21 July 2006; published online 11 September 2006 brain tumor cells adds to our knowledge of the tumor microenvironment in vivo with potential diagnostic and therapeutic implications.

Although early reports identified albumin in brain tumor tissue and associated cystic fluids, the distribution of albumin between poorly differentiated glioma cells and the interstitium was unclear. ${ }^{2-4}$ More recently, albumin with a fluorescent label was found after $24 \mathrm{~h}$ to be 23 -fold higher in the tumor of a C6-glioma model compared to surrounding brain, with the microscopic 'borders' closely corresponding to the distribution of fluorescence. ${ }^{5}$ Another study also detected human glioma xenografts in the subcutaneous tissue of mice by administering fluorescein (F)-labeled HSA. ${ }^{6}$ After noting the prominence of bovine serum albumin (BSA) in lysates of pseudopodia formed by U87 
astrocytoma cells, ${ }^{7}$ we evaluated the distribution of BSA in pseudopodia formed by two migrating astrocytoma cell lines, U87 and LN229. In these studies, the cells' migration was optimized with a chemoattractant, hepatocyte growth factor (HGF). Immunoblots confirmed albumin's preferential pseudopodial distribution along with known pseudopodial proteins. Co-localization of albumin and HGF to pseudopodia was demonstrated on immunoblots and with fluorescence. A lipophilic probe, the chloromethyl derivative of $1,1^{\prime}$-dioctadecyl-3,3, $3^{\prime}$, $3^{\prime}$-tetramethylindocarbocyanine (CM-DiI), was used to label phospholipid plasma membranes. Specificity of albumin's adherence was found for cellular protrusions with simple shapes compared to pseudopodia with irregular contours and connections to multiple pores and other pseudopodia (reticulopodia) or with unmigrated cells.

\section{Materials and methods}

\section{Materials and Cell Culture}

BSA and HSA, both Fraction V, and conjugated with fluorescein isothiocyanate were obtained from Sigma (St Louis, MO, USA). Other reagents were also from Sigma unless otherwise stated. Anti- $\beta$-actin, anti-HSP70, anti-Met (clone 25H2), anti-ezrin, and anti-phosphorylated (p) Met (Y1349) were obtained from Cell Signaling (Beverly, MA, USA). AntiL-plastin and anti-glyceraldehyde-3-phosphate dehydrogenase (GAPDH) were obtained from Biomeda Corp. (Foster City, CA, USA) and Chemicon International (Temecula, CA, USA), respectively. AntiBSA and anti-hepatocyte growth factor (HGF), clone 2612.11 were obtained from Sigma. Alexa Fluor 488 phalloidin and Alexa Fluor 555 anti-mouse IgG were obtained from Molecular Probes, Invitrogen (Carlsbad, CA, USA). Human U87 and LN229 astrocytoma cell lines (American Type Culture Collection, Manassas, VA, USA) were maintained in minimal essential media (MEM) (Cellgro, Media Tech, Herndon, VA, USA) with 10\% fetal bovine serum (FBS) (Invitrogen). Half volumes of media were changed the day prior to each migration assay or harvest of pseudopodia to normalize the cells' metabolic state.

\section{Cell Migration}

Confluent cells were trypsinized on the day of assay and were allowed to recover in media with $10 \%$ FBS for $2 \mathrm{~h}$ at $37^{\circ} \mathrm{C}$. Cells were centrifuged $(<500$ r.p.m., $<5 \mathrm{~min}$ ) and resuspended at $1.5 \times 10^{6} / \mathrm{ml}$ in media with $0.1 \%$ BSA. Modified Boyden chambers with 48 wells (Neuro Probe, Gaithersburgh, MD, USA) were assembled with porous $(8 \mu \mathrm{m})$, polycarbonate filters (Neuro Probe), coated with $0.01 \%$ porcine gelatin. Cell suspensions were added to the upper wells. The lower wells contained media with $0.1 \%$ BSA and chemoattractants (HGF and FBS) as indicated.
The chambers were incubated at $37^{\circ} \mathrm{C}$ for $5-6 \mathrm{~h}$ in $5 \% \mathrm{CO}_{2}$ in routine tissue culture conditions. Upon completion of the assays, the filters were stained with Diff Quik (Fisher Scientific, Pittsburgh, PA, USA) and analyzed. Migrated cells were digitized using a transparency scanner (Epson Perfection 2450 PHOTO, Epson America, Long Beach, CA, USA) and densitometry (UN-SCAN-It gel, Silk Scientific, Orem, UT, USA) with correction for background filter density.

\section{Harvesting Pseudopodia and Unmigrated Cells}

The methodology for obtaining pseudopodia from cells has been described in detail. ${ }^{7}$ Briefly, cell suspensions were loaded in the upper wells of four-, 10-, or single- well Boyden chambers that were assembled with gelatin-coated filters containing either 1 or $3 \mu \mathrm{m}$ pores to separate the upper and lower wells. The $1 \mu \mathrm{m}$ pores were 17 -fold wider than the thickness of two $30 \AA$ lipid bilayers thus potentially accommodating significant amounts of cytoplasm as well as plasma membranes in cell extensions. The lower wells contained MEM fortified with $1 \%$ FBS, with and without HGF, $2.5 \mathrm{ng} / \mathrm{ml}$. Chambers were incubated at $37^{\circ} \mathrm{C}$ in a $5 \% \mathrm{CO}_{2}$ tissue culture incubator for up to $6 \mathrm{~h}$. At designated times, filters were removed, immersed in methanol for $15 \mathrm{~s}$, and then placed on a glass slide with migrated pseudopodia on the filter's undersurface. Nonmigrated cell materials were completely wiped from the top of each filter with Kimwipes or cotton swabs. Fresh Kimwipes or swabs were used to press each filter firmly against the glass slide to promote adherence of migrated pseudopodia to the glass. Unless otherwise stated, the filter was then peeled off the slide with forceps without removing pseudopodia attached to the glass. The layer of adherent pseudopodia was thinner than the filter's $9 \mu \mathrm{m}$ thickness. The slides with attached pseudopodia were stored at $-80^{\circ} \mathrm{C}$. Pseudopodia were either stained for microscopy or solubilized in lysate buffer consisting of $6 \mathrm{M}$ urea, $4 \%$ 3-[(3-cholamidopropyl)dimethylammonio]-1-propanesulfonate, $2 \mathrm{M}$ thiourea, $20 \mathrm{mM}$ dithiothreitol, and $1.6 \mathrm{mM} 4-(2-$ hydroxyethyl)piperazine-1-ethanesulfonic acid, $\mathrm{pH}$ 8.0. The unmigrated cells, mostly whole cells, were allowed to adhere to filters in separate chambers and transferred to glass slides as described for pseudopodia with the upper side of the filter against the glass. Owing to layering, many unmigrated cells were not in contact with the filter pores during the incubations. Protein concentrations were determined with Bradford assays (Coomassie Plus Protein Reagent, Pierce, Rockford, IL, USA).

\section{One-Dimensional Gel Electrophoresis}

Lysates of pseudopodia and unmigrated cells, equalized for total protein content ( $10 \mu \mathrm{g}$ per lane) 
or with GAPDH, as indicated, were electrophoresed in separate lanes of $10 \%$ polyacrylamide gels under reducing conditions. Each gel was stained with Coomassie blue (Novex Colloidal Blue Stain Kit, Invitrogen) and destained with tap water. Protein standards (MagicMark and MultiMark, Invitrogen) were loaded at $8 \mu \mathrm{g}$ per lane.

\section{Protein Identification}

Gels were submitted to the Michigan Proteome Consortium, University of Michigan, Ann Arbor, MI, USA, for robotic dissection of individual Coomassie blue-stained bands that were prominent in lysates of pseudopodia compared to unmigrated cells when total protein was used for equalization. Following trypsin digestion, peptides derived from each band were analyzed with matrix assisted laser desorption ionization time-of-flight mass spectrometry (MALDI-TOF-MS) in 4700 and 4800 Proteomics Analyzers with TOF/TOF Optics (Applied Biosystems, Foster City, CA, USA). Optimized spectra calibrated by trypsin autolysis peaks were used to generate peak lists. Peptide mass fingerprint searches with the Mascot (http://www.matrixscience. com) program and the MS-Fit program (http:// prospector.ucsf.edu) were used for protein identification utilizing the NCBI and SwissProt databases. Search parameters included all species, all $M_{\mathrm{R}}$ 's and pI's, monoisotopic peptide masses, tolerance of $50 \mathrm{ppm} \mathrm{m} / \mathrm{z}$ measurement error and up one missed trypsin cleavage site per peptide, cysteines modified by acrylamide, partial changes of oxidation of methionine and changes at the amino termini, such as conversion of glutamine to pyro-glutamate and acetylation. Trypsin autolysis and keratin-derived peptides were listed as possible contaminants. Protein identifications were accepted when the observed and predicted pI's and $M_{\mathrm{R}}$ 's were consistent and scores indicated nonrandom identifications at a significance level of $P<0.05$.

\section{Immunoblotting}

Gel contents were transferred onto polyvinylidene difluoride membranes (Invitrogen), blocked (Detector Block, Protein Detector Western Blot Kit LumiGLO System, Kirkegaard \& Perry Laboratories, Gaithersburg, MD, USA), and reacted with the designated primary antibodies (anti-BSA (1:20 000), anti- $\beta$-actin (1:1000), anti-HSP70 (1:1000), anti-Lplastin (1:375), anti-GAPDH (1:250), anti-HGF ( $2 \mu \mathrm{g} /$ $\mathrm{ml}$ ), anti-Met (1:1000), anti-pMet (1:375), and anti-ezrin (1:250)). Secondary antibodies, 1:1000 (Kirkegaard \& Perry Laboratories) were horseradish peroxidase-labeled anti-rabbit for antibodies specific for BSA, $\beta$-actin, HSP70, GAPDH, pMet, and ezrin, and anti-mouse for antibodies specific for L-plastin, Met, and HGF. Immunoreactive bands were visualized via horseradish peroxidase's conversion of a luminol-based solution to produce chemiluminescence, and reacted blots were scanned to generate digital images. Relative reactivities of proteins on immunoblots of pseudopodia and unmigrated cells were quantified in digitized bands of chemiluminescence with correction for background.

\section{Fluorescence Microscopy}

To visualize the cellular localization of nonsecreted albumin, $0.25 \mathrm{mg} / \mathrm{ml}$. F-BSA or F-HSA was included in upper and lower wells of Boyden chambers during formation of pseudopodia by cells responding to HGF and FBS or FBS alone. Pseudopodia and unmigrated cells were stained, after removal of filters, for nuclei, actin, HGF, or phospholipid membranes as indicated. Nuclei were stained with Hoechst 33342 trihydrochloride trihydrate (Invitrogen), $10 \mu \mathrm{g} / \mathrm{ml}$. Alexa Fluor 488 phalloidin (green) (1:200) was used to directly stain actin. HGF was indirectly stained with mouse anti-HGF $(2.5 \mu \mathrm{g} / \mathrm{ml})$ and Alexa Fluor 555 goat anti-mouse IgG (1:200). Phosopholipid cell membranes were stained with CM-DiI Cell Tracker (Invitrogen), $1 \mu \mathrm{g} / \mathrm{ml}$, for $5 \mathrm{~min}$ at $37^{\circ} \mathrm{C}$. Cells preloaded with CM-DiI prior to contact with labeled albumin were also evaluated. Pseudopodia and unmigrated cells were examined using an Olympus BH2 microscope with a BHS-RFC reflected light fluorescence attachment (Olympus Corp., Lake Success, NY, USA). Filters appropriate for fluorescent signals from the fluorescein, Hoechst, CM-DiI, and Alexa chromophores were used. Olympus MicroSuite Five Software for Imaging Applications (Soft Imaging System Corp., Lakewood, CO, USA) was used to capture images of multiple emitted fluorescent signals individually. Adobe Photoshop CS2 (Adobe Systems, Inc., San Jose, CA, USA) was used to merge green and red fluorescent signals. Yellow represented similar intensities of merged green and red fluorescent signals.

\section{Results}

\section{Optimized Cell Migration with HGF}

To maximize formation of pseudopodia by U87 and LN229 cells, migration was optimized with growth factor stimulation in the presence of $0.1 \%$ BSA (top and bottom wells). Both HGF and its receptor, Met, are known to be produced by glial cells, including U87 cells. ${ }^{8-14}$ HGF was the most powerful motogen for astrocytoma cell lines, as described by others ${ }^{15}$ and in our limited surveys of growth factors. Although U87 cells migrated and formed pseudopodia in media with FBS, adding HGF improved their migration. HGF greatly enhanced the migration of multiple astrocytoma cell lines compared to FBS alone, with LN229 cells consistently achieving levels comparable to the robust migration of U87 
cells. Response curves indicated that $2.5 \mathrm{ng} / \mathrm{ml}$ HGF was an optimal concentration in the presence of 0.1-1\% FBS (not shown). The average density of migrated U87 and LN229 cells increased 3.5- and 17.4-fold, respectively, above background migration (no chemoattractants) in response to HGF, $2.5 \mathrm{ng} / \mathrm{ml}$, and $0.1 \%$ FBS (Figure 1).

\section{Mass Spectrometric Identification of Proteins Increased in Lysates of Pseudopodia on 1D Gels}

We have previously reported the 2D electrophoretic proteome $(20-100 \mathrm{kDa})$ of pseudopodia formed by U87 cells protruding through filters with $3 \mu \mathrm{m}$ pores. $^{7}$ In this study, bands in $1 \mathrm{D}$ gels consistent with the $M_{\mathrm{R}}$ 's of BSA, $68 \mathrm{kDa}$ and its dimerized form

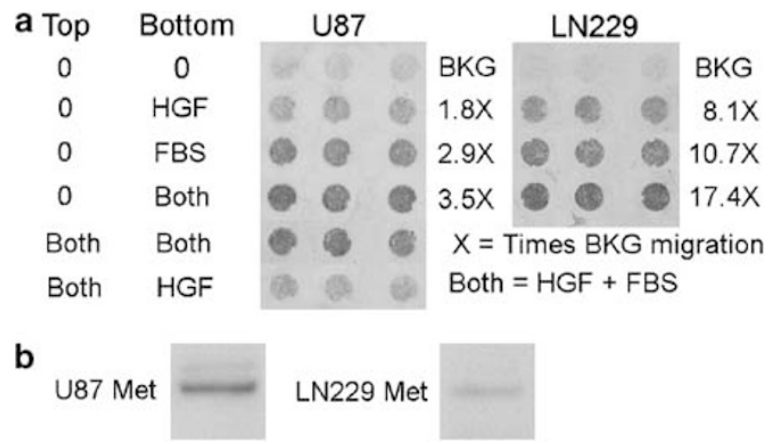

Figure 1 Astrocytoma cell migration in response to hepatocyte growth factor (HGF) and fetal bovine serum (FBS). (a) Astrocytoma cells, U87 and LN229, migrated through gelatin-coated filters with $8 \mu \mathrm{m}$ pores in Boyden chambers for $6 \mathrm{~h}$ in response to HGF, $2.5 \mathrm{ng} / \mathrm{ml}$, and $0.1 \% \mathrm{FBS}$, in either the top or bottom wells or both, as indicated for each row. The media in all wells also contained $0.1 \%$ BSA. The uppermost rows show background migration (BKG) without HGF and FBS for each cell line. Although U87 cells migrated in media with FBS at 2.9-fold times BKG, adding HGF improved migration 3.5-fold. LN229 cells with almost no BKG were maximally stimulated (17.4-fold) by HGF and FBS to 17.4-fold. Each disc of migrated cells was $3 \mathrm{~mm}$ in diameter. Diff Quik stain. $\mathrm{X}=$ Times BKG. Both $=$ HGF + FBS. (b) Immunoblots of the HGF receptor, Met $(145 \mathrm{kDa})$, in lysates of unmigrated, unstimulated adherent cells in routine culture conditions. Levels of Met varied for each cell line as demonstrated with anti-Met.
$(140 \mathrm{kDa})$, were increased in lysates of pseudopodia compared to unmigrated cells. Visible bands containing BSA as the predominant protein identified with MS are indicated (*) in Figure 2. Nine peptides were identified in the $68 \mathrm{kDa}$ band of the lysate from pseudopodia formed by LN229 cells (1 $\mu \mathrm{m}$ pores). Seven peptides that matched with BSA are listed in Table 1. The MALDI-TOF/TOF-MS/MS spectrum from one BSA-derived peptide is shown in Figure 3. In U87 cells, L-plastin ( $62 \mathrm{kDa}$ ) was identified as a co-migrating protein of lower abundance than BSA in pseudopodia; its two matching peptides are listed as the last two entries in Table 1. The amounts of BSA on Coomassie-stained 1D gels appeared to be greater in U87 pseudopodia formed by protrusion through $1 \mu \mathrm{m}$ compared to $3 \mu \mathrm{m}$ pores (not shown). Sources of BSA in the lysates included FBS used

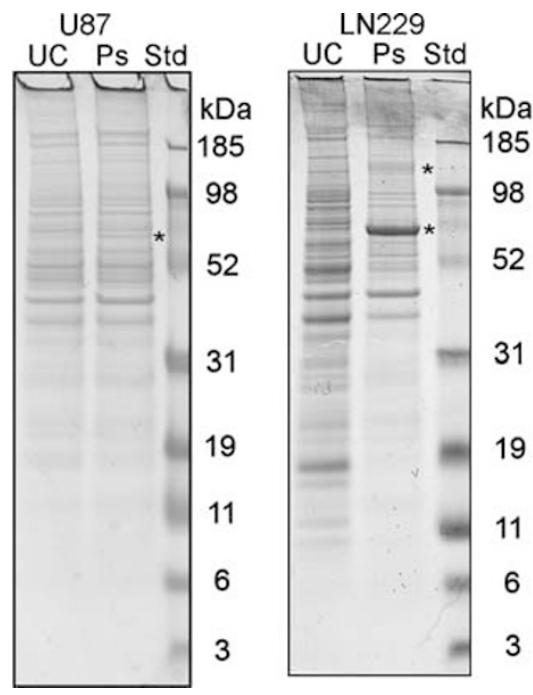

Figure 2 One-dimensional (1D) SDS-PAGE gels of U87 and LN229 pseudopodia and unmigrated cells. Lysates prepared from pseudopodia (Ps) of both cell lines contained BSA that was increased compared to unmigrated cells (UC). Bands (visible in Ps but not UC) that contained predominantly BSA, identified as tryptic peptides with mass spectrometry (MS), are indicated $(*)$. Peptides obtained from the $68 \mathrm{kDa}$ band from Ps formed by LN229 cells are listed in Table 1. Each lane contained $10 \mu \mathrm{g}$ total protein. Coomassie blue stain.

Table 1 MS-MS peptide summary for the $68 \mathrm{kDa}$ band in lysate of pseudopodia formed by cultured astrocytoma cells

\begin{tabular}{|c|c|c|c|c|c|c|c|c|}
\hline$\#$ & Observed mass & Calc. mass & Ion score $C I \%$ & Ion score & Sequence & Start res. & End res. & Error (ppm) \\
\hline 1 & 1479.7731 & 1479.80 & 99.993 & 81 & LGEYGFQNALIVR & 421 & 433 & -18.2 \\
\hline 2 & 1567.72 & 1567.74 & 99.838 & 67 & DAFLGSFLYEYSR & 347 & 359 & -12.8 \\
\hline 3 & 1439.7947 & 1439.81 & 97.594 & 56 & RHPEYAVSVLLR & 360 & 371 & -10.6 \\
\hline 4 & 1880.8998 & 1880.92 & 99.162 & 60 & RPCFSALTPDETYVPK & 508 & 523 & -10.7 \\
\hline 5 & 1740.8259 & 1740.83 & 99.129 & 60 & MPCTEDYLSLILNR & 469 & 482 & -2.4 \\
\hline 6 & 1639.907 & 1639.94 & 99.989 & 79 & KVPQVSTPTLVEVSR & 437 & 451 & -20.1 \\
\hline 7 & 1724.8135 & 1724.83 & 99.950 & 72 & MPCTEDYLSLILNR & 469 & 482 & -9.6 \\
\hline 8 & 1069.4985 & 1069.63 & 99.999 & 65 & LSPEELLLR & 207 & 215 & -122.9 \\
\hline 9 & 1675.6543 & 1675.85 & 99.877 & 46 & FSLVGIGGQDLNEGHR & 416 & 431 & -166.8 \\
\hline
\end{tabular}

Tryptic digestion of this band from pseudopodia formed by LN229 cells yielded peptides 1-7 that matched 'albumin [Bos taurus]', Accession $\#=30794280$. In pseudopodia formed by U87 cells, in addition to peptides derived from BSA; peptides 8-9 matched 'Lymphocyte cytosolic protein 1 (L-plastin) [Homo sapiens]', Accession $\#=8217500$. Ion scores greater than 30 were considered to be significant for protein identification. $\mathrm{CI}=$ confidence interval. 
during cell culture and migration, as well as BSA, $1 \mathrm{mg} / \mathrm{ml}$, added during the assay. No human albumin (potentially from cells stimulated by HGF) was detected.

\section{Protein Comparisons on Immunoblots of Pseudopodia and Unmigrated Cell Lysates}

Specific antibodies were used to demonstrate protein distributions between pseudopodia and unmigrated cells. After determining that BSA was an overwhelming constituent of lysates from pseudopodia protruded through $1 \mu \mathrm{m}$ pores, GAPDH was used as a loading control in immunoblots instead of total protein. Equalized loadings for unmigrated cells with pseudopodia derived from U87 (3 and $1 \mu \mathrm{m}$ pores), and LN229 (1 $\mu \mathrm{m}$ pores) cells were indicated by equal amounts of GAPDH ( $36 \mathrm{kDa})$. To detect distinct bands for BSA as a monomer and dimer, anti-BSA required a 1:20 000 dilution. Higher

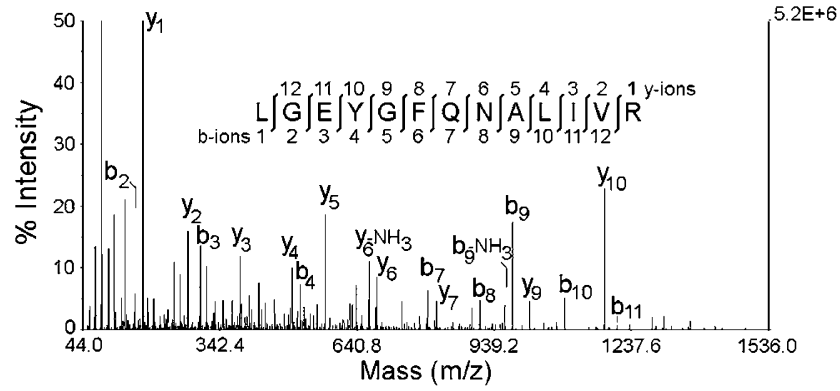

Figure 3 MALDI-TOF/TOF-MS/MS spectrum for a BSA peptide listed in Table 1, with a $[\mathrm{M}+\mathrm{H}]^{+}$precursor ion of mass/charge $(\mathrm{m} / \mathrm{z})$ ratio 1479.77 . Tryptic digestion of the $68 \mathrm{kDa}$ band from a lysate of pseudopodia formed by LN229 cells included a match for the peptide sequence ${ }^{421}$ LGEYGFQNALIVR $^{433}$ (ion score $=81$ ), derived from albumin [Bos taurus].

Table 2 Ratios of indicated proteins in the lysates of pseudopodia compared to unmigrated cells that are shown on immunoblots (Figure 4)

\begin{tabular}{lccc}
\hline Pseudopodia & U87 3 $\mu \mathrm{m}$ & U87 1 $\mu \mathrm{m}$ & LN229 1 $\mu \mathrm{m}$ \\
\hline GAPDH & 0.91 & $0.95^{\mathrm{a}}$ & 1.04 \\
Ezrin & 1.09 & $1.16^{\mathrm{a}}$ & 1.99 \\
$\beta$-Actin & 1.44 & 1.92 & 3.82 \\
BSA total & 1.59 & 7.94 & 3.05 \\
$\quad$ Monomer & 1.34 & 6.15 & 1.71 \\
Dimer & 2.05 & 15.50 & 7.82 \\
\hline
\end{tabular}

GAPDH was used to standardize loading of lysates. Exogenous albumin, especially its dimerized form, was increased in the pseudopodia compared to GAPDH or ezrin, a membrane associated protein found in pseudopodia. ${ }^{19-23}$ Dimerized BSA was also increased compared to $\beta$-actin which has been previously shown to be increased in pseudopodia. ${ }^{7,17,18}$ The cell types and pore sizes of the filters used are listed in the top row.

${ }^{\mathrm{a}}$ The results for anti-ezrin in U87 cells with pseudopodia formed on filters with $1 \mu \mathrm{m}$ pores were obtained from a repeat blot loaded with the same amounts of lysates. Results for anti-GAPDH were repeated. The ratio for GAPDH on the first blot was 1.08. concentrations of anti-BSA reacted strongly and diffusely with the entire lanes of pseudopodial lysates. Ezrin and actin demonstrated increased distributions in pseudopodia that were slight to moderate. However, reactivities for BSA, were increased, up to 15.5-fold for the dimerized form in pseudopodia extended through $1 \mu \mathrm{m}$ pores compared to unmigrated cells (Figure 4 and Table 2). Reactivities for HGF $(70 \mathrm{kDa})$ and pMet (145 kDa) were increased in pseudopodia up to 3.04- and 6.37fold, respectively, compared to unmigrated cells. However, reactivities for L-plastin $(62 \mathrm{kDa})$ and heat shock protein 70 (HSP70) (73 kDa), were greater in

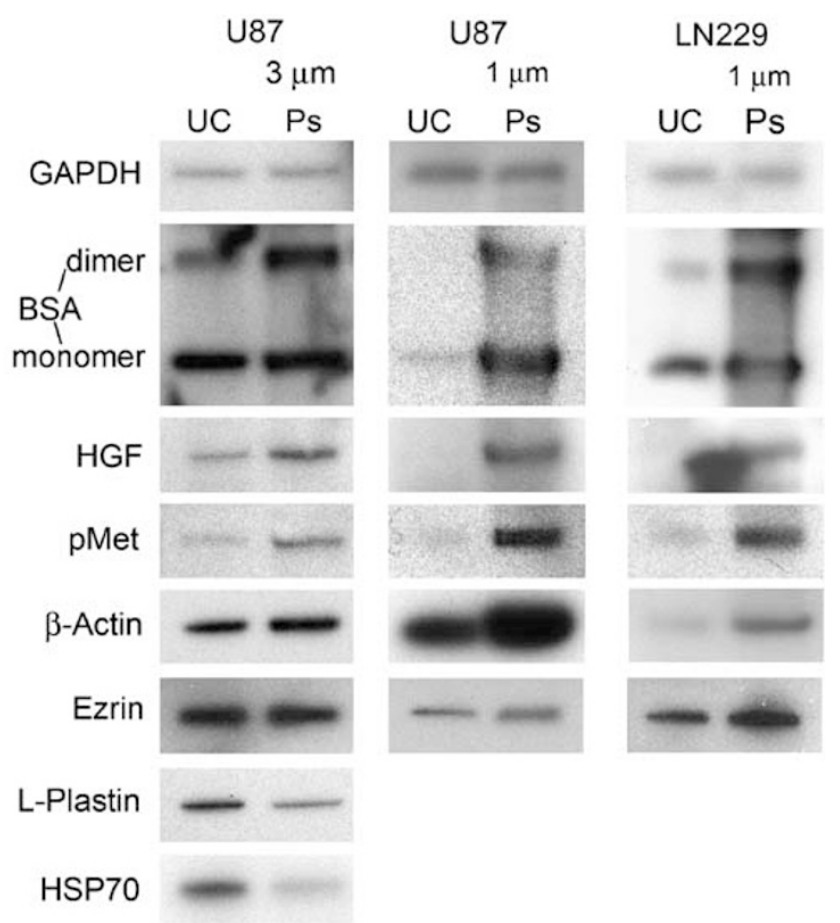

Figure 4 Distributions of proteins in astrocytoma pseudopodia and unmigrated cells on immunoblots. Pseudopodia (Ps) were formed on filters in response to serum and HGF for $4-5 \mathrm{~h}$ and harvested as lysates. Unmigrated cells (UC) from the opposite side of the filters were also harvested. Specific antibodies were used to demonstrate protein distributions. Glyceraldehyde-3-phosphate dehydrogenase (GAPDH) ( $36 \mathrm{kDa}$ ) was used to equalize loadings for UC with Ps derived from U87 cells on filters (3 and $1 \mu \mathrm{m}$ pores), and LN229 cells ( $1 \mu \mathrm{m}$ pores). Anti-BSA required a 1:20 000 dilution to detect distinct bands for BSA in lanes of pseudopodial lysate. Higher concentrations reacted so strongly that the bands were obscured. Reactivities for BSA, either its monomeric $(68 \mathrm{kDa})$ or dimerized $(140 \mathrm{kDa})$ forms, in Ps were increased up to 15.5-fold with the greater increases occurring in Ps formed using filters with $1 \mu \mathrm{m}$ pores. Table 2 lists specific results that demonstrated increased albumin content in Ps vs UC in ratios that are comparable or higher than established pseudopodial proteins ( $\beta$-actin and ezrin). Reactivities for HGF $(70 \mathrm{kDa})$ and pMet (145 kDa), were increased in Ps up to 3.04- and 6.37-fold, respectively, compared to UC. However, reactivities for L-plastin (62 kDa) and heat shock protein 70 (HSP70) $(73 \mathrm{kDa})$, proteins that co-migrated with BSA and HGF, were greater in UC than Ps, 1.96- and 2.94-fold, respectively. The results for antiezrin in U87 cells with Ps formed on filters with $1 \mu \mathrm{m}$ pores were obtained from a second blot loaded with the same amounts of lysates and with results repeated for GAPDH. 
unmigrated cells, 1.96 and 2.94-fold, respectively, than in pseudopodia (Figure 4). In a separate immunoblot, no immunoreactivity for L-plastin was found in BSA, Fraction V (not shown).

\section{Co-Localizations of HGF, $\beta$-Actin, F-BSA, and CM-DiI to Pseudopodia}

HGF and actin are proteins previously found to be increased in lysates of U87 pseudopodia compared to unmigrated cells. ${ }^{7}$ These proteins also localized to profiles of pseudopodia with fluorescent staining. Merged fluorescent signals (yellow) from HGF (red) and $\beta$-actin (green) were found on LN229 pseudopodia that protruded through $1 \mu \mathrm{m}$ pores of filters at $5 \mathrm{~h}$ in response to serum and HGF. Actin was highlighted directly with Alexa Fluor 488 phalloidin and HGF was demonstrated with indirect immunofluoresence via anti-HGF and Alexa Fluor 555 anti-mouse IgG. Signals from HGF appeared to be especially prominent at the tips of actin-rich pseudopodia. Images of unmigrated cells with signals from HGF, actin, and nuclei stained blue
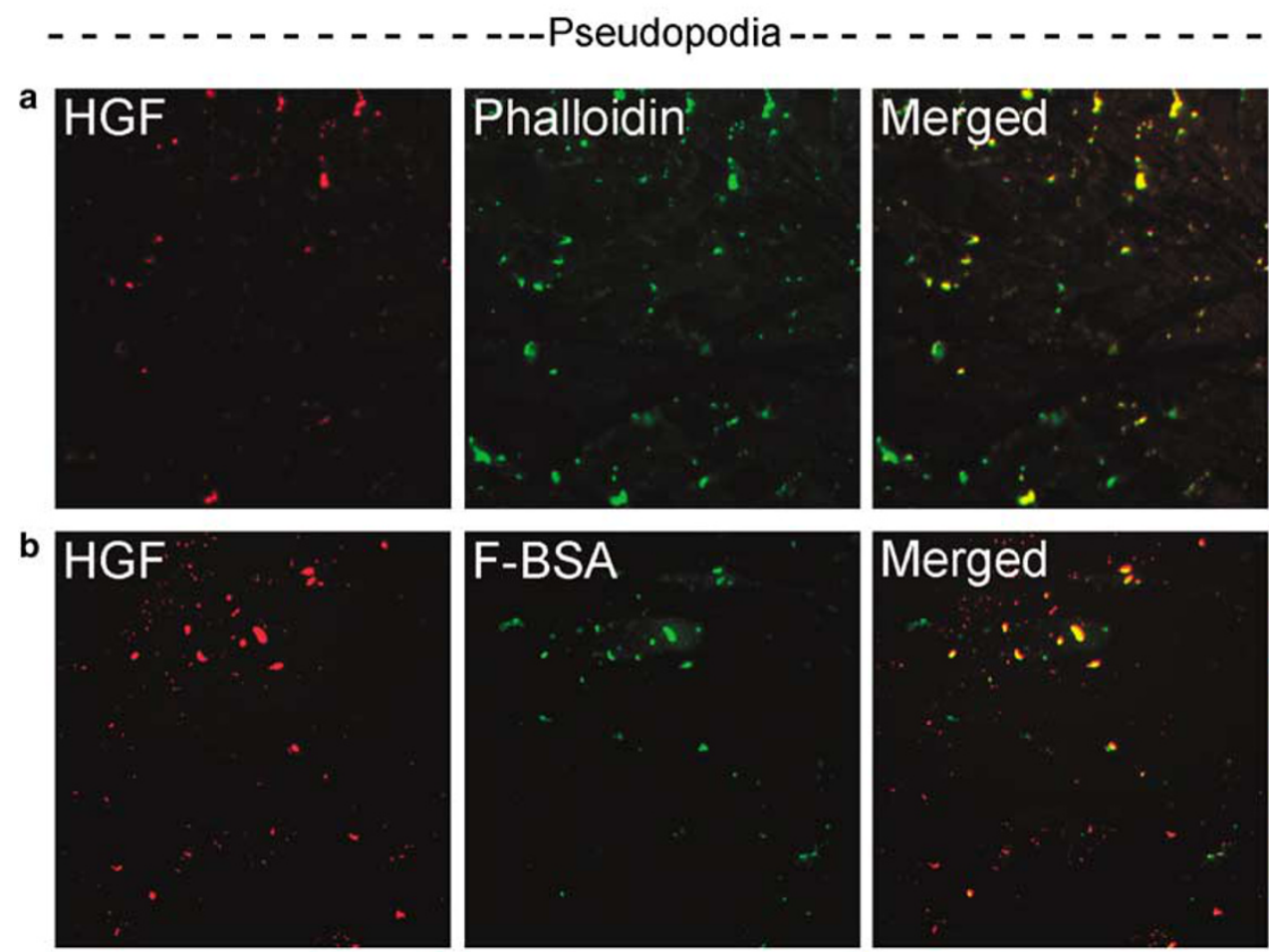

Unmigrated
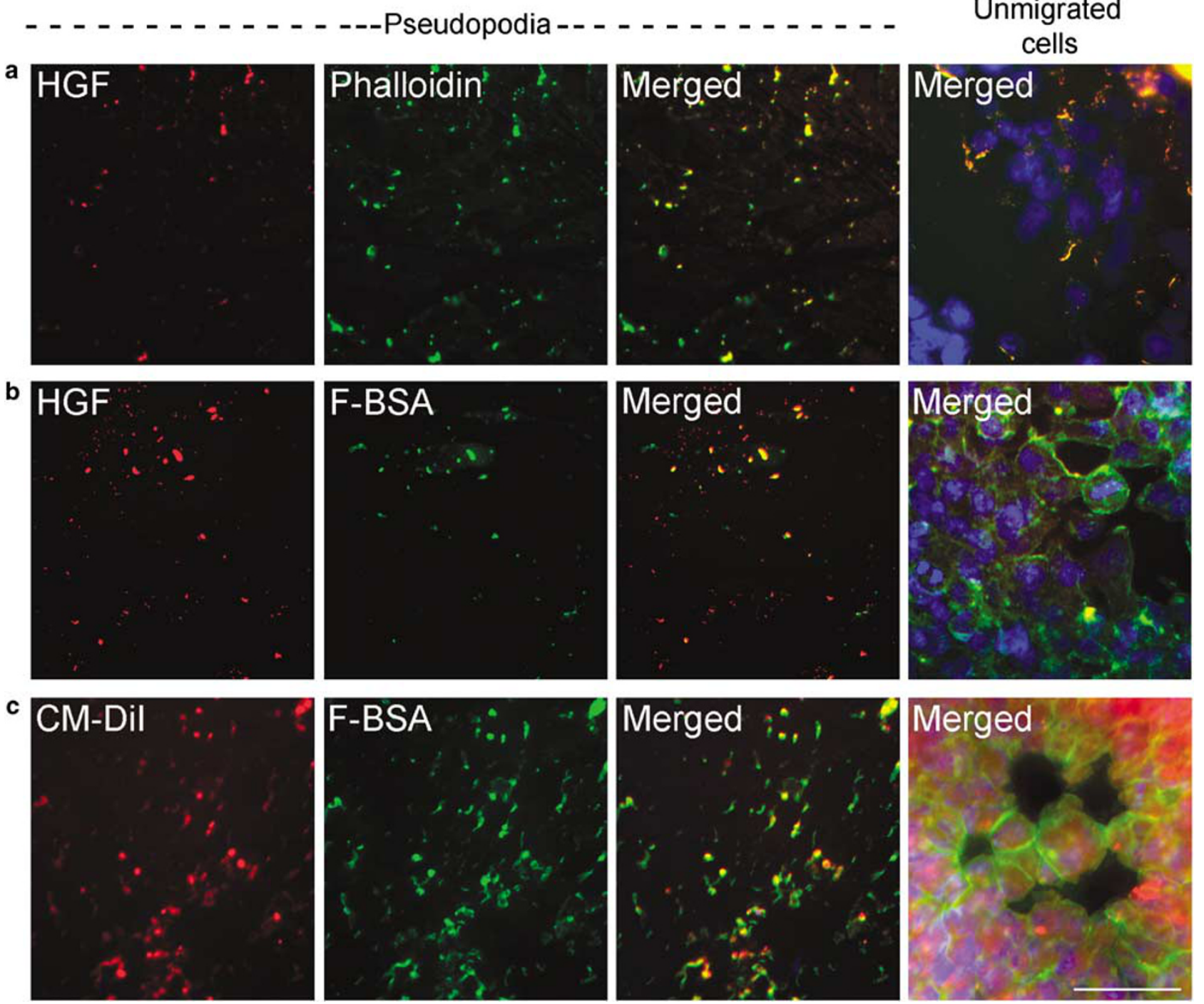

Figure 5 Co-localization of HGF and actin to pseudopodia of LN229 cells. Pseudopodia were formed on filters by cells responding to serum and HGF. (a) Fluorescent signals from HGF (red) and actin (green) were merged (yellow) on pseudopodia and unmigrated cells. HGF was demonstrated with indirect immunofluoresence via anti-HGF and Alexa Fluor 555 anti-mouse IgG. $\beta$-Actin was highlighted directly with Alexa Fluor 488 phalloidin. Nuclei were stained with Hoechst (blue). Signals from HGF appeared to be especially prominent at the tips of actin-rich pseudopodia. Focally, the membranes (possibly early protrusions) of unmigrated cells showed colocalization of HGF and actin. Pseudopodia protruded through filters with $1 \mu \mathrm{m}$ pores for $5 \mathrm{~h}$. (b) HGF also co-localized with fluorescein (F) isothiocyanate-labeled BSA (green) on pseudopodia and focally on the membranes of unmigrated cells. Pseudopodia protruded through gelatin-coated filters with $1 \mu \mathrm{m}$ pores for $5 \mathrm{~h}$ in the presence of F-BSA. (c) F-BSA also co-localized with CM-DiI diffusely on pseudopodial membranes and focally on cell membranes. Pseudopodia protruded through filters with $3 \mu \mathrm{m}$ pores for 1.5 in the presence of F-BSA. CM-DiI was added after the assay. In all assays unmigrated cells were adherent to separate filters. Pseudopodia and unmigrated cells were fixed, transferred to glass slides, and filters were removed. The magnification bar represents $25 \mu \mathrm{m}$. 
with Hoechst were merged. Occasional foci on the peripheral membranes of unmigrated cells showed co-localization of HGF and actin; some intense foci of co-localized signals appeared to be protrusions (Figure 5a). Under the same conditions, HGF also co-localized with F-BSA on pseudopodia and focally on the membranes of unmigrated cells (Figure 5b). F-BSA also co-localized with CM-DiI diffusely on LN229 pseudopodial membranes but only focally on cellular plasma membranes. In the assays with CM-DiI present, pseudopodia formed in response to serum and HGF using filters with $3 \mu \mathrm{m}$ pores for $1.5 \mathrm{~h}$. CM-DiI was added after the assay (Figure 5c).

\section{Localization of F-BSA on Filter-Bound Pseudopodia}

When F-BSA or F-HSA, $0.25 \mathrm{mg} / \mathrm{ml}$, was included in the media of migrating cells, labeled albumin was found to localize on pseudopodia that protruded through filters with 1 or $3 \mu \mathrm{m}$ pores in Boyden chambers. The difference in F-BSA's signals for U87 pseudopodia vs unmigrated cells could be seen directly on the filters. The fluorescence of pseudopodia embedded and protruding through the $1 \mu \mathrm{m}$ pores on the bottom surface of a filter was much brighter (Figure 6a) than signals from unmigrated cells on the upper filter surface (Figure 6b). Background adherence of F-BSA to the gelain-coated filters appeared to be minimal or none. In all other assays, pseudopodia and unmigrated cells were transferred to glass slides with firm pressure and filters were removed prior to microscopic evaluation.

\section{Adherence of F-BSA to Pseudopodia Formed in Response to Serum, with and without HGF}

Adherence of F-BSA to pseudopodial tips occurred during U87 cell migration in response to either FBS alone or FBS and HGF. However, the more complexshaped pseudopodia and reticulopodia that formed within $1.5 \mathrm{~h}$ (faster than LN229 cells) associated with F-BSA much less strongly and at lesser intensities that were typical of unmigrated cells (Figure 7).

\section{Time Course for F-BSA Adherence to Pseudopodia and Reticulopodia}

A time course for migration of LN229 cells through $3 \mu \mathrm{m}$ filter pores demonstrated F-BSA on pseudopodia predominantly during $1-2 \mathrm{~h}$ of migration in response to HGF and FBS. The F-BSA signals on pseudopodia diminished to levels for unmigrated cells at later time points as the pseudopodia became complex and merged to form reticulopodia with origins from multiple pores (Figure 8). The range of signals from F-BSA on unmigrated cells was
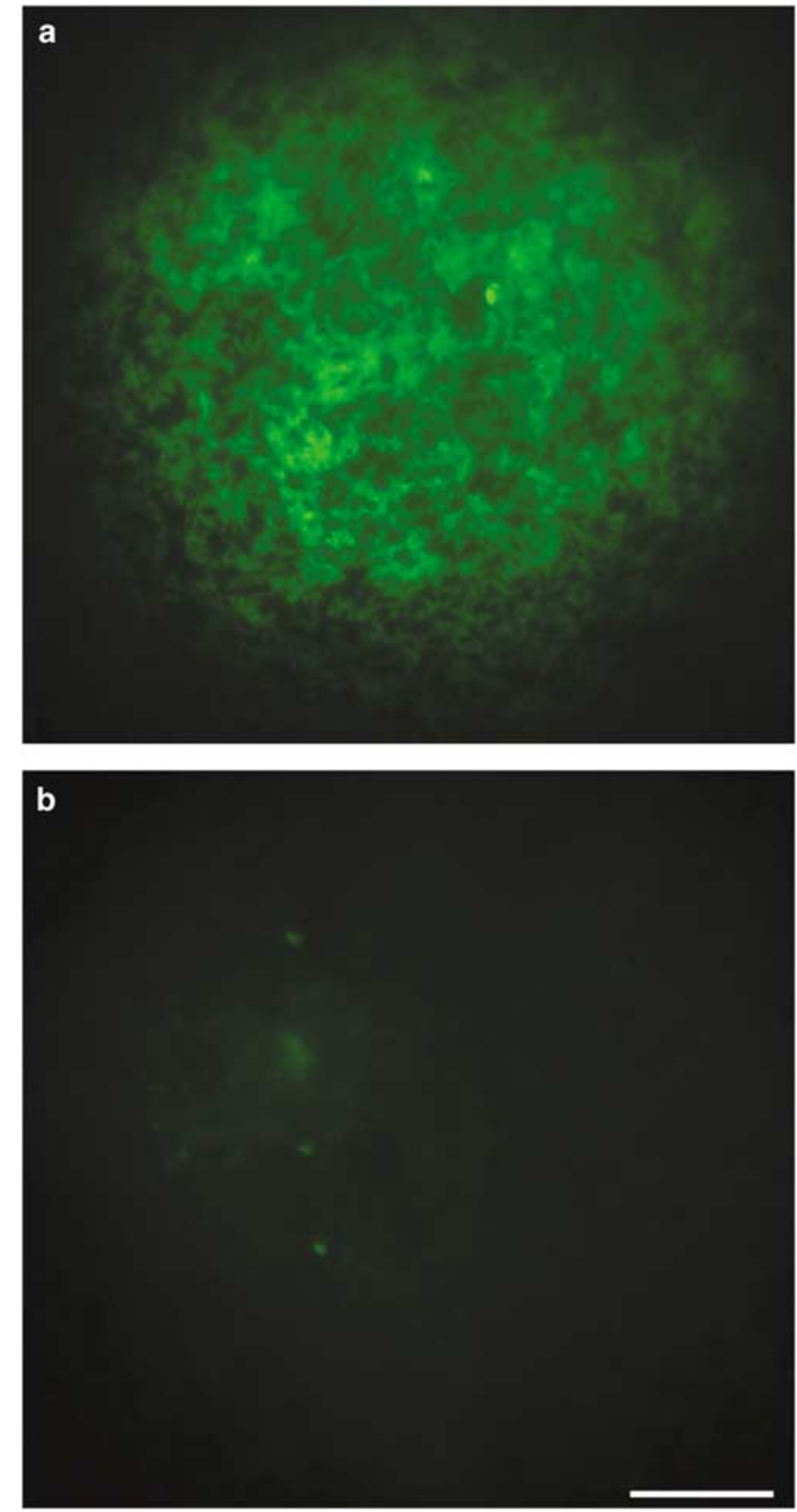

Figure 6 Distributions of fluorescently labeled BSA on U87 pseudopodia and unmigrated cells responding to HGF and FBS. (a) Abundant green signals from F-BSA coated the protrusions of U87 cells within and extending through $1 \mu \mathrm{m}$ pores of a gelatincoated filter after $4 \mathrm{~h}$ of exposure to HGF and FBS in the bottom well of a Boyden chamber. (b) The unmigrated U87 cells on the upper surface of a filter from a separate chamber demonstrated a much smaller amount of F-BSA. No other labels or stains were present. Pseudopodia and unmigrated cells were not removed from filters in this assay. No fluorescence was detected from the gelatin-coated filters. The magnification bar represents $25 \mu \mathrm{m}$.

comparable but the signals were not as evenly distributed as those from pseudopodia formed during 1-2 h. Cells were preloaded with CM-DiI and nuclei were stained after the assay with Hoechst. The signals from CM-DiI on pseudopodia, reticulopodia, and unmigrated cells persisted at the same intensity throughout the time course with 


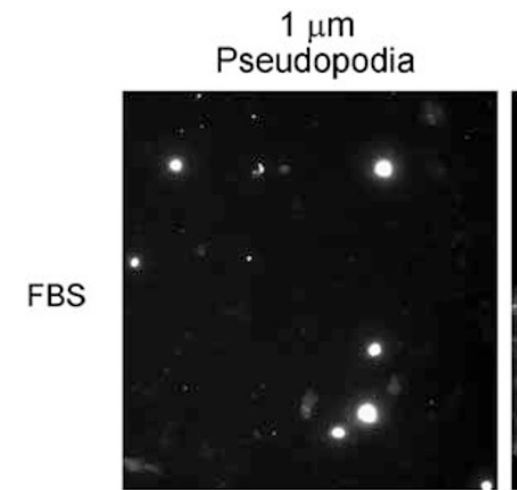

\section{Unmigrated cells}
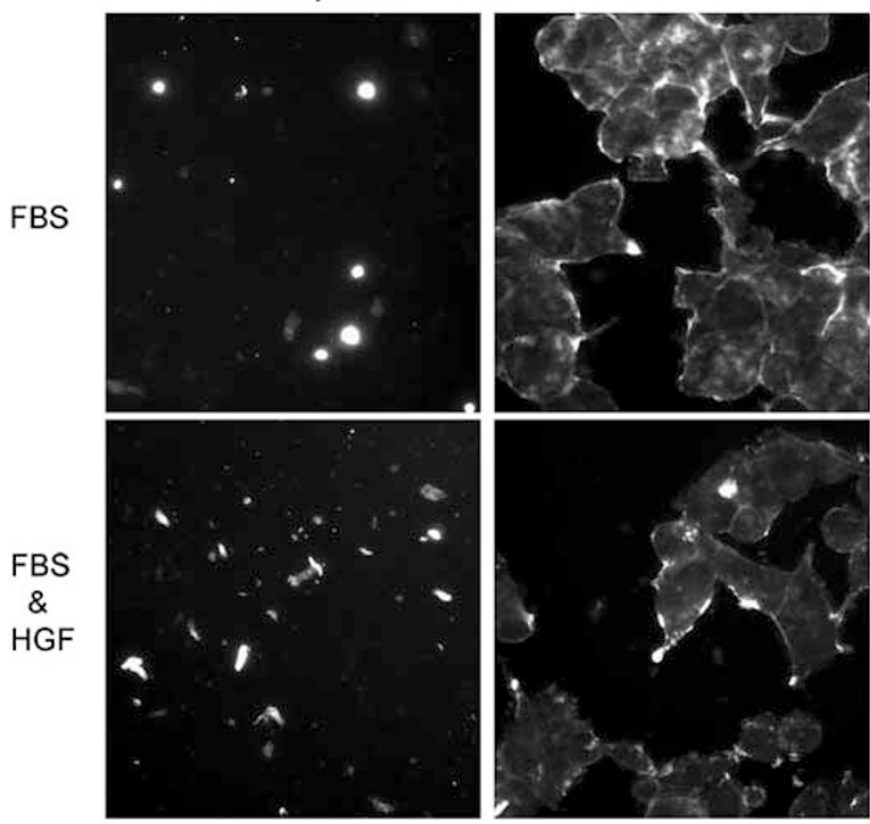
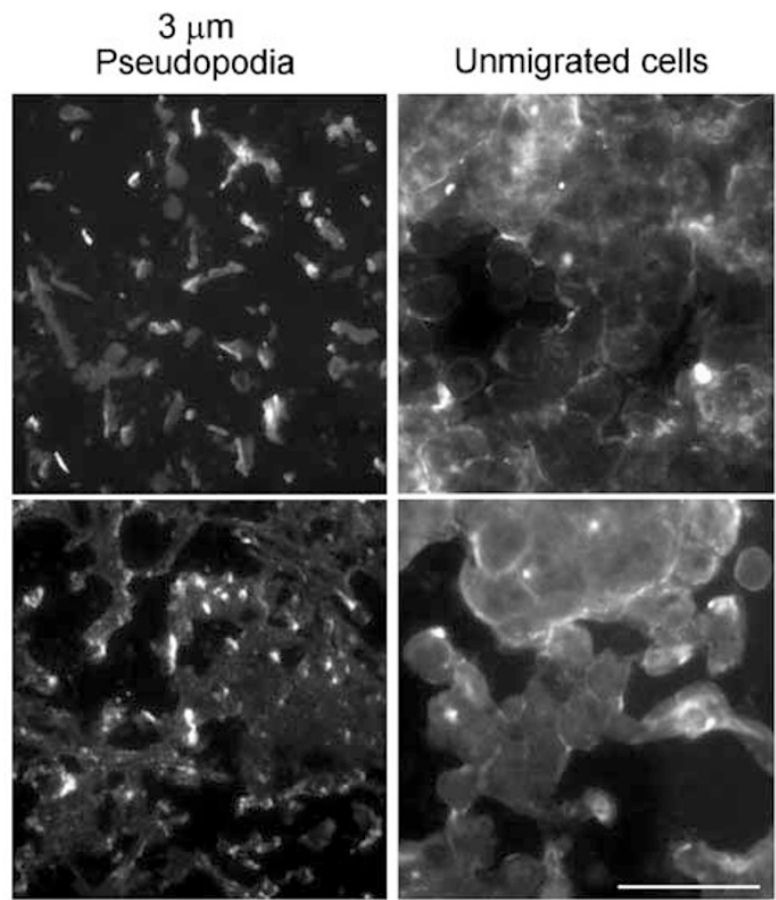

Figure 7 Adherence of F-BSA to small pseudopodia of U87 cells responding to FBS or FBS and HGF. Cells extended pseudopodia brightly labeled with F-BSA through $1 \mu \mathrm{m}$ pores. A combination of vividly labeled small pseudopodia and dimmer more complex cytoplasmic extensions were formed when filters with $3 \mu \mathrm{m}$ pores were used. Unmigrated cells from the opposite sides of separate filters demonstrated focal membranous labeling with occasional accentuation at the tips of cytoplasmic extensions, possibly in the vicinity of where underlying $1 \mu \mathrm{m}$ filter pores had been present. The extreme brightness of labeled pseudopodial tips protruded through $1 \mu \mathrm{m}$ pores in response to FBS obscured their shapes when photographed but some were slightly elongated. No other stains or labels were present. Assays were 1.5-2 h. The green fluorescence of F-BSA was converted to white. The magnification bar represents $25 \mu \mathrm{m}$.

exceptions of some pseudopodia with extremely bright F-BSA signals. The changes in signals from CM-DiI were not as dramatic as those from F-BSA. A repeat time course for LN229 cells yielded similar results. Signals from F-HSA on pseudopodia formed by U87 cells also initially included bright signals that became subdued at later time points (not shown).

\section{Discussion}

Traditionally, pseudopodia have been studied in cells migrating on flat surfaces. However, pseudopodial protrusion through small tissue spaces, such as gaps in the neuropil of the brain, is more common in vivo. The $1-3 \mu \mathrm{m}$ pores of gelatin-coated filters recapitulated gaps in tissue. Although others have demonstrated selective accumulation of serum albumin in astrocytomas ${ }^{5,6}$ and to some extent on glioma cells, ${ }^{4,16}$ this study demonstrated preferential accumulation of albumin on or in pseudopodia of astrocytoma cells using gels, immunoblots, and fluorescent labeling. Protein bands that were increased in pseudopodial lysates on 1D electrophoretic gels were confirmed to be BSA with MS. On immunoblots, with lysate loading equalized for levels of GAPDH, BSA was increased to levels comparable or greater than those of known pseudo- podial proteins, $\beta$-actin and ezrin. The increases in dimerized BSA were especially dramatic. Actin is well-established as being enriched in pseudopodia. ${ }^{7,17,18}$ Ezrin, a membrane cytoskeletal crosslinker, has been found to associate with pseudopodia, lamellipodia, and peripheral astrocytic processes. ${ }^{19-23}$ To confirm BSA's association with pseudopodia, co-localization was noted with HGF and plasma membranes labeled with CM-DiI but BSA was not found on the gelatin-coated filters. The traditional phospholipid membrane marker, CM-DiI, has been used to label both neuronal and glial cells. ${ }^{24-30}$ No difference was found in the distribution of CM-DiI in the membranes with either pre- or postassay labeling methods. The signals of labeled albumin on pseudopodia decreased with formation of reticulopodia and were qualitatively greater on pseudopodia compared to unmigrated cells. The signals from CM-DiI remained relatively constant at dimmer levels of intensity. As a marker of pseudopodial protrusion, albumin can be used to further investigate the events involved in initiating tumor invasion. Although U87 cells appeared to form reticulopodia more quickly than LN229 cells, both cell types initially produced small pseudopodia and a subpopulation of larger elongated pseudopodia that were strongly labeled with F-BSA.

The preferential accumulation of serum albumin in astrocytomas has been largely attributed to 

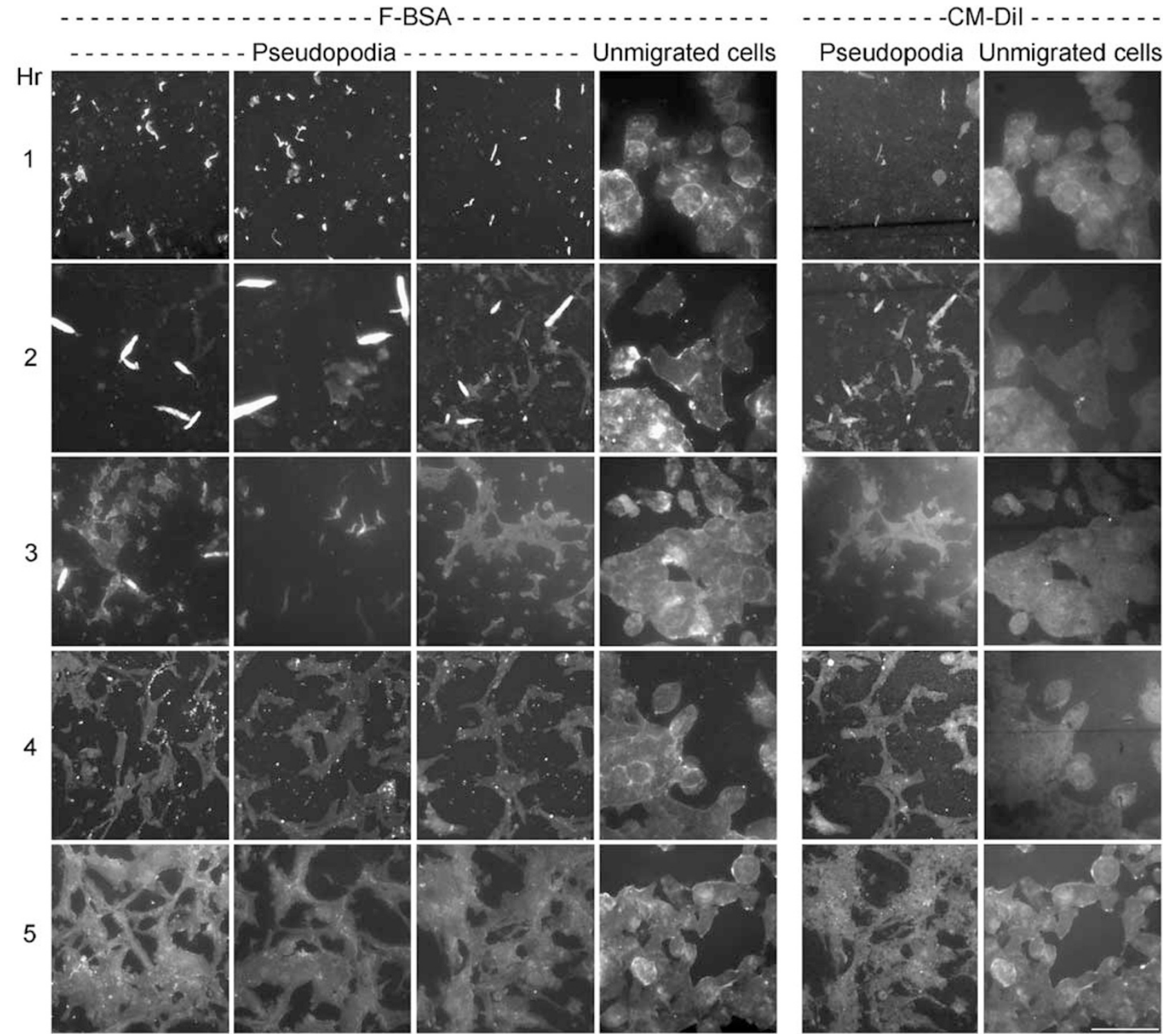

Figure 8 Preferential adherence of F-BSA to newly-formed pseudopodia of LN229 cells in a time course study. Although the F-BSA signals demonstrated profiles of pseudopodia vividly during the first $2 \mathrm{~h}$, the signals dimmed at later time points. The newly formed pseudopodia at $1-2 \mathrm{~h}$ appeared to arise from single pores, whereas at $3-5 \mathrm{~h}$, they were mostly syncytial (reticulopodia) with contributions from multiple pores. The unmigrated cells from the upper side of the filters displayed irregular signals from F-BSA rather than the evenly distributed signals on profiles of pseudopodia formed during the first $2 \mathrm{~h}$. The cell membranes were loaded with CM-DiI prior to the assay. Nuclei were stained with Hoechst after each time point (not shown). The most dramatic changes in signal intensities were found in the filter range for F-BSA. The fluorescent signals of F-BSA (green) and DiI (red) were converted to white. Correspondence of F-BSA and CM-DiI can be seen for unmigrated cells and the adjacent columns of pseudopodia. The magnification bar represents $25 \mu \mathrm{m}$.

increased permeability of the BBB in these tumors, ${ }^{31,32}$ possibly aided by the ability of astrocytic cells to ingest albumin. ${ }^{4,16}$ Albumin has a large capacity and high affinity for fatty acids so that the pool of circulating HSA in the bloodstream quantitatively forms an important source of lipids for delivery to tumor cells, with or without the aid of various fatty acid-binding proteins in the recipient cells. ${ }^{33}$ Patterns and rates of fatty acid incorporation by glial cells have been found to vary according to the degree of cellular differentiation. ${ }^{34}$ High levels of albumin are routinely present in brain tissue during early development ${ }^{35-37}$ which may deliver fatty acids during rapid growth. Although HGF has the potential to induce production and secretion of albumin by nonhepatic cells, ${ }^{38-41}$ only exogenous albumin was detected in lysates of tumor pseudopodia in this study.

Albumin's localization to newly formed pseudopodia of migrating astrocytoma cells suggests the possibility that its cargo of fatty acids would be available for remodeling and assembly of phospholipid membranes in cell protrusions during tumor invasion. Although intracellular accumulation of fatty acids is cytotoxic in nonadipose tissues, rapid fatty acid utilization by membranes would permit a 
high rate of fatty acid uptake. ${ }^{42}$ In fetal rats, growth cones at the ends of axons are membrane rich, $75 \%$ lipid structures that grow by adding exogenous fatty acids locally to membranes rather than via the cell body. ${ }^{43}$ Serum albumin traversing a leaky BBB and codispersing with tumor cells along white matter tracts could provide fatty acids that aid rapidly forming pseudopodia. In melanoma cells, fatty acids delivered by BSA were shown to support formation of pseudopodia. ${ }^{44}$ Although oxidation of fatty acids could also provide energy for cell migration, we found that glycolysis alone can support astrocytoma and melanoma cell migration. ${ }^{45,46}$

Localization of HGF to pseudopodia of astrocytoma cells was also confirmed on immunoblots and with immunofluorescence. HGF has been associated with rapid changes in the calcium levels of cells ${ }^{47-49}$ and loosening of intercellular junctions. ${ }^{50}$ Albumin's supply of fatty acids would support rapid formation of pseudopodia by cells responding to HGF, serum, or cytokines and other growth factors. Co-localization of blood products, such as albumin, via the permeable BBB in astrocytomas in vivo with HGF produced by tumor cells may help to initiate cell migration during tissue invasion.

The localization of albumin on pseudopodia of astrocytoma cells could play a role in novel therapies. Suppressive treatments of invasive cells could be specifically targeted by albumin's delivery of toxic fatty acids ${ }^{51}$ or chemotherapy drugs ${ }^{52}$ to pseudopodia. Also, delivery of oleic acid in acidosis would support a toxic configuration of $\alpha$-lactalbumin, an approach under development as an anticancer agent that spares normal tissues. ${ }^{53-61}$ However, if permeability of the BBB in brain tumors is considered as a means to introduce a toxic effect on tumors via albumin, then the uncommon diseases that also cause dysfunction of the BBB, such as Guillain-Barre syndrome and chronic inflammatory demyelinating polyneuropathy ${ }^{32}$ would have to be ruled out to avoid damaging non-neoplastic tissues.

Labeling migrating cells with F-BSA provided a marker of pseudopodia that highlighted their morphology in vitro. Markers of tumor invasion are needed to evaluate anti-invasion treatments with imaging in vivo. Preferential localization of fluorescent albumin to pseudopodia supports the proposal by others to use fluorescent albumin for delineating the leading edge of invasive brain tumors. ${ }^{5,6}$ Albumin can also be labeled with a paramagnetic metal, for example, gadolinium (Gd), for use in magnetic resonance imaging. ${ }^{62-68}$ Proteins complexed with Gd retain their functions, ${ }^{6,69}$ and Gd-albumin has been visualized in brain tumors. ${ }^{31,70}$ Therefore, Gd-albumin's potential localization to pseudopodia may correlate with invasion in vivo after it leaks through the BBB of astrocytomas during imaging studies. Thus, labeled albumin may serve as a useful marker of pseudopodia and as an agent to tailor anti-invasion treatments.

\section{Acknowledgements}

We thank Esther $\mathrm{P}$ Jane, PhD, Department of Neurosurgery, University of Pittsburgh, for advice on fluorescent microscopy and The Michigan Proteome Consortium, University of Michigan, Ann Arbor, MI, for technical assistance. We thank The Nick Eric Wichman Foundation and The Beez Foundation for financial support and encouragement, and we gratefully acknowledge support from DoD/TATRC USAMRMC grant 04145001.

\section{References}

1 Geer CP, Grossman SA. Interstitial fluid flow along white matter tracts: a potentially important mechanism for the dissemination of primary brain tumors. J Neurooncol 1997;32:193-201.

2 Seitz RJ, Wechsler W. Immunohistochemical demonstration of serum proteins in human cerebral gliomas. Acta Neuropathol (Berlin) 1987;73:145-152.

3 Murray KJ, Ausman JI, Chou SN, et al. Immunoproteins in human brain tumor cyst fluids. J Neurosurg 1977;46:314-319.

4 Brett M, Weller RO. Intracellular serum proteins in cerebral gliomas and metastatic tumours: an immunoperoxidase study. Neuropathol Appl Neurobiol 1978; $4: 263-272$.

5 Kremer P, Wunder A, Sinn $\mathrm{H}$, et al. Laser-induced fluorescence detection of malignant gliomas using fluorescein-labeled serum albumin: experimental and preliminary clinical results. Neurol Res 2000;22: 481-489.

6 Ichioka T, Miyatake S, Asai N, et al. Enhanced detection of malignant glioma xenograft by fluorescein-human serum albumin conjugate. J Neurooncol 2004;67:47-52.

7 Beckner ME, Chen X, An J, et al. Proteomic characterization of harvested pseudopodia with differential gel electrophoresis and specific antibodies. Lab Invest 2005;85:316-327.

8 Abounader R, Ranganathan S, Lal B, et al. Reversion of human glioblastoma malignancy by U1 small nuclear RNA/ribozyme targeting of scatter factor/hepatocyte growth factor and c-met expression. J Natl Cancer Inst 1999;91:1548-1556.

9 Hollborn M, Krausse C, Iandiev I, et al. Glial cell expression of hepatocyte growth factor in vitreoretinal proliferative disease. Lab Invest 2004;84:963-972.

10 Koochekpour S, Jeffers M, Rulong S, et al. Met and hepatocyte growth factor/scatter factor expression in human gliomas. Cancer Res 1997;57:5391-5398.

11 Lamszus K, Laterra J, Westphal M, et al. Scatter factor/ hepatocyte growth factor (SF/HGF) content and function in human gliomas. Int J Dev Neurosci 1999; 17:517-530.

12 Welch WC, Kornblith PL, Michalopoulos GK, et al. Hepatocyte growth factor (HGF) and receptor (c-met) in normal and malignant astrocytic cells. Anticancer Res 1999;19:1635-1640.

13 Yamada T, Yoshiyama Y, Tsuboi Y, et al. Astroglial expression of hepatocyte growth factor and hepatocyte growth factor activator in human brain tissues. Brain Res 1997;762:251-255. 
14 Yano H, Hara A, Murase S, et al. Expression of hepatocyte growth factor and matrix metalloproteinase-2 in human glioma. Brain Tumor Pathol 2001; 18:7-12.

15 Brockmann MA, Ulbricht U, Gruner K, et al. Glioblastoma and cerebral microvascular endothelial cell migration in response to tumor-associated growth factors. Neurosurgery 2003;52:1391-1399; discussion 1399.

16 Wolff M, Boker DK. Immunohistochemical demonstration of immunoglobulins and albumin in human brain tumors. Clin Neuropathol 1989;8:72-78.

17 Le PU, Nguyen TN, Drolet-Savoie P, et al. Increased beta-actin expression in an invasive moloney sarcoma virus-transformed MDCK cell variant concentrates to the tips of multiple pseudopodia. Cancer Res 1998; 58:1631-1635.

18 Nguyen TN, Wang HJ, Zalzal S, et al. Purification and characterization of beta-actin-rich tumor pseudopodia: role of glycolysis. Exp Cell Res 2000;258:171-183.

19 Lamb RF, Ozanne BW, Roy C, et al. Essential functions of ezrin in maintenance of cell shape and lamellipodial extension in normal and transformed fibroblasts. Curr Biol 1997;7:682-688.

20 Derouiche A, Frotscher M. Peripheral astrocyte processes: monitoring by selective immunostaining for the actin-binding ERM proteins. Glia 2001;36: 330-341.

21 Alhaja E, Adan J, Pagan R, et al. Anti-migratory and anti-angiogenic effect of p16: a novel localization at membrane ruffles and lamellipodia in endothelial cells. Angiogenesis 2004;7:323-333.

22 Song J, Fadiel A, Edusa V, et al. Estradiol-induced ezrin overexpression in ovarian cancer: a new signaling domain for estrogen. Cancer Lett 2005;220: 57-65.

23 Elliott BE, Meens JA, SenGupta SK, et al. The membrane cytoskeletal crosslinker ezrin is required for metasis of breast cancer cells. Breast Cancer Res 2005;7:R365-R373.

24 Honig MG, Hume RI. Fluorescent carbocyanine dyes allow living neurons of identified origin to be studied in long-term cultures. J Cell Biol 1986;103:171-187.

25 Godement P, Vanselow J, Thanos S, et al. A study in developing visual systems with a new method of staining neurones and their processes in fixed tissue. Development 1987;101:697-713.

26 Liljelund P, Levine JM. Dynamic behavior of the ends of growing parallel fibers in early postnatal rat cerebellum. J Neurobiol 1998;36:91-104.

27 Skaliora I, Adams R, Blakemore C. Morphology and growth patterns of developing thalamocortical axons. J Neurosci 2000;20:3650-3662.

28 Isbister CM, O’Connor TP. Filopodial adhesion does not predict growth cone steering events in vivo. J Neurosci 1999;19:2589-2600.

29 Kageyama GH, Robertson RT. Transcellular retrograde labeling of radial glial cells with WGA-HRP and DiI in neonatal rat and hamster. Glia 1993;9:70-81.

30 Reese BE, Maynard TM, Hocking DR. Glial domains and axonal reordering in the chiasmatic region of the developing ferret. J Comp Neurol 1994;349:303-324.

31 Cavagna FM, Maggioni F, Castelli PM, et al. Gadolinium chelates with weak binding to serum proteins. A new class of high-efficiency, general purpose contrast agents for magnetic resonance imaging. Invest Radiol 1997;32:780-796.
32 Brettschneider J, Claus A, Kassubek J, et al. Isolated blood-cerebrospinal fluid barrier dysfunction: prevalence and associated diseases. J Neurol 2005;252: 1067-1073.

33 Glatz JF, Luiken JJ, van Nieuwenhoven FA, et al. Molecular mechanism of cellular uptake and intracellular translocation of fatty acids. Prostaglandins Leukot Essent Fatty Acids 1997;57:3-9.

34 Robert J, Montaudon D, Hugues P. Incorporation and metabolism of exogenous fatty acids by cultured normal and tumoral glial cells. Biochim Biophys Acta 1983;752:383-395.

35 Dziegielewska KM, Evans CA, Lorscheider FL, et al. Plasma proteins in fetal sheep brain: blood-brain barrier and intracerebral distribution. J Physiol 1981; 318:239-250.

36 Uriel J, Trojan J, Dubouch P, et al. Intracellular alphafetoprotein and albumin in the developing nervous system of the baboon. Pathol Biol (Paris) 1982;30: 79-83.

37 Skultetyova I, Tokarev DI, Jezova D. Albumin content in the developing rat brain in relation to the bloodbrain barrier. Endocr Regul 1993;27:209-213.

38 Schwartz RE, Linehan JL, Painschab MS, et al. Defined conditions for development of functional hepatic cells from human embryonic stem cells. Stem Cells Dev 2005;14:643-655.

39 Wang PP, Wang JH, Yan ZP, et al. Expression of hepatocyte-like phenotypes in bone marrow stromal cells after HGF induction. Biochem Biophys Res Commun 2004;320:712-716.

40 Kang XQ, Zang WJ, Bao LJ, et al. Fibroblast growth factor-4 and hepatocyte growth factor induce differentiation of human umbilical cord blood-derived mesenchymal stem cells into hepatocytes. World J Gastroenterol 2005;11:7461-7465.

41 McGuckin CP, Forraz N, Baradez MO, et al. Production of stem cells with embryonic characteristics from human umbilical cord blood. Cell Prolif 2005;38: $245-255$.

42 van der Vusse GJ, van Bilsen M, Glatz JF, et al. Critical steps in cellular fatty acid uptake and utilization. Mol Cell Biochem 2002;239:9-15.

43 Auestad N, Innis SM. Dietary n-3 fatty acid restriction during gestation in rats: neuronal cell body and growth-cone fatty acids. Am J Clin Nutr 2000;71 (1 Suppl):312S-314S.

44 Hodgson L, Kohn EC, Dong C. Extracellular lipidmediated signaling in tumor-cell activation and pseudopod protrusion. Int J Cancer 2000;88:593-600.

45 Beckner ME, Gobbel GT, Abounader R, et al. Glycolytic glioma cells with active glycogen synthase are sensitive to PTEN and inhibitors of PI3K and gluconeogenesis. Lab Invest 2005;85:1457-1470.

46 Beckner ME, Stracke ML, Liotta LA, et al. Glycolysis as primary energy source in tumor cell chemotaxis. J Natl Cancer Inst 1990;82:1836-1840.

47 Baffy G, Yang L, Michalopoulos GK, et al. Hepatocyte growth factor induces calcium mobilization and inositol phosphate production in rat hepatocytes. J Cell Physiol 1992;153:332-339.

48 Osada S, Saji S, Nakamura T, et al. Cytosolic calcium oscillations induced by hepatocyte growth factor (HGF) in single fura-2-loaded cultured hepatocytes: effects of extracellular calcium and protein kinase C. Biochim Biophys Acta 1992;1135: 229-232. 
49 Kawanishi T, Kato T, Asoh H, et al. Hepatocyte growth factor-induced calcium waves in hepatocytes as revealed with rapid scanning confocal microscopy. Cell Calcium 1995;18:495-504.

50 Grisendi S, Arpin M, Crepaldi T. Effect of hepatocyte growth factor on assembly of zonula occludens-1 protein at the plasma membrane. J Cell Physiol 1998; 176:465-471.

51 Hawash IY, Hu XE, Adal A, et al. The oxygensubstituted palmitic acid analogue, 13-oxypalmitic acid, inhibits Lck localization to lipid rafts and $\mathrm{T}$ cell signaling. Biochim Biophys Acta 2002;1589:140-150.

52 Gradishar WJ. Albumin-bound paclitaxel: a nextgeneration taxane. Expert Opin Pharmacother 2006;7: 1041-1053.

53 Svensson M, Mossberg AK, Pettersson J, et al. Lipids as cofactors in protein folding: stereo-specific lipidprotein interactions are required to form HAMLET (human alpha-lactalbumin made lethal to tumor cells). Protein Sci 2003;12:2805-2814.

54 Duringer C, Hamiche A, Gustafsson L, et al. HAMLET interacts with histones and chromatin in tumor cell nuclei. J Biol Chem 2003;278:42131-42135.

55 Svanborg C, Agerstam H, Aronson A, et al. HAMLET kills tumor cells by an apoptosis-like mechanismcellular, molecular, and therapeutic aspects. Adv Cancer Res 2003;88:1-29.

56 Gustafsson L, Leijonhufvud I, Aronsson A, et al. Treatment of skin papillomas with topical alphalactalbumin-oleic acid. N Engl J Med 2004;350: 2663-2672.

57 Baltzer A, Svanborg C, Jaggi R. Apoptotic cell death in the lactating mammary gland is enhanced by a folding variant of alpha-lactalbumin. Cell Mol Life Sci 2004;61:1221-1228.

58 Fischer W, Gustafsson L, Mossberg AK, et al. Human alpha-lactalbumin made lethal to tumor cells (HAMLET) kills human glioblastoma cells in brain xenografts by an apoptosis-like mechanism and prolongs survival. Cancer Res 2004;64:2105-2112.

59 Fast J, Mossberg AK, Nilsson H, et al. Compact oleic acid in HAMLET. FEBS Lett 2005;579:6095-6100.
60 Fast J, Mossberg AK, Svanborg C, et al. Stability of HAMLET-a kinetically trapped alpha-lactalbumin oleic acid complex. Protein Sci 2005;14:329-340.

61 Permyakov SE, Pershikova IV, Zhadan AP, et al. Conversion of human alpha-lactalbumin to an apolike state in the complexes with basic poly-amino acids: toward understanding of the molecular mechanism of antitumor action of HAMLET. J Proteome Res 2005;4:564-569.

62 Reuben J. Gadolinium (3) as a paramagnetic probe for proton relaxation studies of biological macromolecules. Binding to bovine serum albumin. Biochemistry 1971;10:2834-2838.

63 Lauffer RB, Brady TJ. Preparation and water relaxation properties of proteins labeled with paramagnetic metal chelates. Magn Reson Imaging 1985;3:11-16.

64 Hnatowich DJ. Label stability in serum of four radionuclides on DTPA-coupled antibodies-an evaluation. Int J Rad Appl Instrum B 1986;13:353-358.

65 Parmelee DJ, Walovitch RC, Ouellet HS, et al. Preclinical evaluation of the pharmacokinetics, biodistribution, and elimination of MS-325, a blood pool agent for magnetic resonance imaging. Invest Radiol 1997; 32:741-747.

66 Lauffer RB, Parmelee DJ, Dunham SU, et al. MS-325: albumin-targeted contrast agent for MR angiography. Radiology 1998;207:529-538.

67 Caravan P, Cloutier NJ, Greenfield MT, et al. The interaction of MS-325 with human serum albumin and its effect on proton relaxation rates. J Am Chem Soc 2002;124:3152-3162.

68 Adzamli K, Yablonskiy DA, Chicoine MR, et al. Albumin-binding MR blood pool agents as MRI contrast agents in an intracranial mouse glioma model. Magn Reson Med 2003;49:586-590.

69 Artemov D, Mori N, Ravi R, et al. Magnetic resonance molecular imaging of the HER-2/neu receptor. Cancer Res 2003;63:2723-2727.

70 Neuwelt EA, Specht HD, Hill SA. Permeability of human brain tumor to $99 \mathrm{mTc}$-gluco-heptonate and 99mTc-albumin. Implications for monoclonal antibody therapy. J Neurosurg 1986;65:194-198. 